\title{
Curing characteristics, swelling, and mechanical properties of natural rubber/nitrile butadiene rubber blends with and without compatibilizer
}

\author{
Arum Yuniari*, Hesty Eka Mayasari, Ike Setyorini \\ Center for Leather, Rubber, and Plastics, Jl. Sokonandi No. 9 Yogyakarta, 55166, Indonesia \\ *Corresponding author. Tel.: +62 274 512929, 563939, Fax: +62 274563655 \\ E-mail: arumyuniari@yahoo.com
}

Received: 14 August 2017 Revised: 12 September 2017 Accepted: 5 October 2017

\begin{abstract}
The use of methyl methacrylate butadiene styrene (MBS) as a compatibilizer for natural rubber (NR) and nitrile butadiene rubber (NBR) blends has been investigated. Research on the cure characteristics, mechanical properties, swelling, and morphology (SEM) has been conducted to determine the compatibility of NR/NBR blends in the presence of MBS. Based on the cure characteristics, it is indicated that the presence of MBS was affected significantly by maximum and minimum torque. The addition of MBS improved the mechanical properties and the oil resistance of NR/NBR blends due to the compatibility and better interfacial adhesion between rubber phases. The experiment showed that MBS loading by $2.5 \mathrm{phr}$ was the optimum level for NR/NBR blends.
\end{abstract}

Keywords: NR, NBR, MBS, compatibilizer, blending.

\section{INTRODUCTION}

Blending of two or more polymers to get the desired product has commonly been carried out nowadays in the manufacturing industry. The properties of polymer blends can be made using different formulation and composition. The dispersion of each component influences the final properties of the blend (Ahmad et al., 2015). Unfortunately, some other properties such as modulus and tensile strength may be reduced as the consequence of the incompatibility between the components (Wisittanawat et al., 2014), so that compatibilizers as the third component are needed in the process of blending two immiscible polymers. The interfacial tension of the blend composition can be reduced using compatibilizers and better interfacial adhesion is generated (Angnanon et al., 2011).

Natural rubber (NR) is abundant and it has excellent mechanical properties and processability. But it has poor oil resistance and is sensitive to ozone, light, moisture, and heat due to its double bonds (Alipour et al., 2011; Siriyong \& Keawwattana, 2012). Acrylonitrile butadiene rubber (NBR) has excellent oil-resistant properties over a wide range of temperatures as well as excellent resistance to abrasion, water, alcohols, and heat. But it has poor dielectric properties and resistance to ozone (Ismail et al., 2009). NBR requires a reinforcing filler to improve its mechanical properties or blending with other rubber (ElSabbagh \& Yehia, 2007).

The blending of NR with NBR is intended to produce a vulcanizate with good mechanical and oil-resistant properties. NBR has poor compatibility with NR because of their differences in polarity and solubility. Compatibilizer as a compatibilizing agent is needed to improve the compatibility of NBR/NR blends. Some compatibilizers had been studied by previous researchers. Grafted natural rubber (GNR) was applied as a compatibilizer for NR/NBR blends and improved the mechanical properties and oil resistance. But, it decreased the interfacial tension between the rubber constituents (Angnanon et al., 2011). Ahmad et al. (2015) studied epoxidized natural tubber (ENR 50) as a compatibilizer for natural rubber-recycled acrylonitrile butadiene rubber (NR/NBR). Incorporation of ENR 50 into NR/NBR gave better adhesion and increased the crosslink density. ENR caused higher minimum torque $\left(\mathrm{M}_{\mathrm{L}}\right)$ and maximum torque which indicated difficult processability of the blends. The use of epoxidized 
natural rubber (ENR) as a compatibilizer was studied by (Kinasih \& Fathurrohman, 2016; Thomas et al., 2012; Kantala et al., 2009; Abu-Abdeen \& Elamer, 2010; Ahmad et al., 2015; Rajasekar et al., 2009).

Methyl methacrylate-butadiene-styrene resin (MBS resin) has rubber particles dispersed throughout a matrix of methyl methacrylate-styrene polymer. It has a good balance of transparency and impact resistance (Takahashi et al., 2015). Styrene and methyl methacrylate (MMA) are grafted onto styrene butadiene rubber (SBR) or poly(butadiene) (PB) particles so that MBS is a typical core-shell rubber modifier (Mousavi \& Amraei, 2015; Ren et al., 2014). MBS is an impact modifier polymer that contains 0.01 to 5 percent (w/w) of the polymers of at least one compound of the formula, wherein $\mathrm{R}_{1}$ and $\mathrm{R}_{2}$ are $\mathrm{C}_{1}$ to $\mathrm{C}_{4}$ alkyl, $\mathrm{R}_{3}$ and $\mathrm{R}_{4}$ are $\mathrm{HC}_{1}$ to $\mathrm{C}_{4}$ alkyl, or 4-hydoxy 2'- $\mathrm{R}_{2}$ 5'- $\mathrm{R}_{1}$-phenyl. MBS polymer is an impact modifiers against thermal oxidative degradation and discoloration and improve dispersibility (Clikeman, 1981). The study of NR/NBR blends using MBS as a compatibilizer has never been conducted by any previous reseachers. The curing characteristics, swelling, and mechanical properties of NR/ NBR blends with MBS as a compatibilizer were investigated in this paper.

\section{MATERIALS AND METHODS \\ Materials}

NBR (Krynac 4975) Mooney viscosity ML (1+4) $100{ }^{\circ} \mathrm{C}(75 \pm 5) \mathrm{ACN} 48.5 \pm 1.5 \%$, NR (RSS) by PTPN IX Semarang, carbon black N330 and N774 ex. OCI used as a filler, paraffin wax (Antilux 654 A), parafinic oil (Indrasari, Semarang) as a softener, $\mathrm{ZnO}$ (Indoxide) and stearic acid (Aflux $42 \mathrm{M}$ ) (Rhein Chemie) as an activator, TMQ (Kemai) as an antioxidant, 6PPD (Starchem) as an antiozonant, TMTD and MBTS (Shandong) as accelerators, sulfur (Miwon) as a vulcanizing agent, and methyl methacrylate butadiene styrene (MBS) ZB-521 ZB-32 (Huaxing) as a compatibilizer.

\section{Methods \\ Equipments}

The following equipment was used in this research: a two-roll mill, an oscillating disc rheometer (Geotech 3000 A), a hydraulic press (MN Vulcanizing Press, Spec XLB, D 400 x 400 x 1), digital analytical tools, a tensile strength tester (Kao Tieh 7010), a hardness tester (Toyoseiki), scanning electron microscope (Mini SEM SNE $3200 \mathrm{M}$ ), DSC (Perkin Elmer), and an oven (Memmert).

\section{Preparation of the NR/NBR Compound}

The formulation of NR/NBR blends is presented in Table 1. The rubber compounds were prepared using a laboratory mixing roll mill at a roller temperature by $40 \pm 10^{\circ} \mathrm{C}$. NBR was masticated for 6 minutes and blended with NR. The homogenization of the rubber blend about 6 minutes, after that the other additives were added. The rubber compounds were allowed to stand overnight before vulcanization.

\section{Cure Characteristics}

The cure characteristics of NR/NBR/MBS compounds were determined at three different temperatures, i.e. 140,150 and $160{ }^{\circ} \mathrm{C}$ using an oscillating disc rheometer (Geotech $3000 \mathrm{~A}$ ) in accordance with the ISO 3417 method. The scorch time $\left(\mathrm{t}_{\mathrm{S} 2}\right)$, optimum curing time $\left(\mathrm{t}_{\mathrm{c} 90}\right)$, and torque (minimum and maximum) were determined from the rheograph. The cure rate index (CRI), which is a measure of the rate of the crosslinking reaction (Marković et al., 2007), was calculated using Equation (1)

$\mathrm{CRI}=\frac{100}{\mathrm{t}_{\mathrm{c} 90}-\mathrm{t}_{\mathrm{S} 2}}$

\section{Mechanical Properties}

Mechanical properties, such as tensile strength and elongation at break, were measured using Kao Tieh model KT 7010 at a crosshead speed of 500 $\mathrm{mm} / \mathrm{min}$ and at $25 \pm 2{ }^{\circ} \mathrm{C}$ according to the ISO 37 standard testing method. The shore hardness measurement of the specimens was measured using a durometer type A according to the ISO 48 testing method.

\section{Swelling Properties}

The resistance of the vulcanizates to IRM 903 was determined using the method described in ISO 1817 at the ambient temperature for 72 hours. The change in the weight of the samples was expressed as the swelling precentage:

$\%$ swelling $=\frac{\mathrm{W}_{2}-\mathrm{W}_{1}}{\mathrm{~W}_{1}}$

where $\mathrm{W}_{1}$ and $\mathrm{W}_{2}$ are the initial weight and the final weight of the swollen sample, respectively. 
Table 1. Formulation of the blends.

\begin{tabular}{lrrrrrrr}
\hline Ingredients (phr)* & P0 & P1 & P2 & P3 & P4 & P5 & P6 \\
\hline RSS & 50 & 50 & 50 & 50 & 50 & 50 & 50 \\
NBR & 50 & 50 & 50 & 50 & 50 & 50 & 50 \\
ZnO & 5 & 5 & 5 & 5 & 5 & 5 & 5 \\
Stearic acid & 1 & 1 & 1 & 1 & 1 & 1 & 1 \\
N330 & 20 & 20 & 20 & 20 & 20 & 20 & 20 \\
N774 & 20 & 20 & 20 & 20 & 20 & 20 & 20 \\
6 PPD & 2 & 2 & 2 & 2 & 2 & 2 & 2 \\
TMQ & 2 & 2 & 2 & 2 & 2 & 2 & 2 \\
Paraffin wax & 0.5 & 0.5 & 0.5 & 0.5 & 0.5 & 0.5 & 0.5 \\
MBTS & 1.5 & 1.5 & 1.5 & 1.5 & 1.5 & 1.5 & 1.5 \\
TMTD & 0.5 & 1.5 & 1.5 & 1.5 & 1.5 & 1.5 & 1.5 \\
Paraffinic oil & 10 & 10 & 10 & 10 & 10 & 10 & 10 \\
MBS & 0 & 2.5 & 5.0 & 7.5 & 10 & 12.5 & 15 \\
Sulfur & 1.5 & 1.5 & 1.5 & 1.5 & 1.5 & 1.5 & 1.5 \\
\hline
\end{tabular}

$*$ phr $=$ part per hundred

\section{Morphological Observation}

Morphology is a major factor for rubber blends, which determines the extent to which the blends are compatible. Scanning electron microscope (SEM) was done using Mini SEM SNE $3200 \mathrm{M}$ with up to $3000 \mathrm{x}$ magnification.

\section{Thermal Analysis}

The thermal properties of NR/NBR blends were determined using DSC (Perkin Elmer) according to the ASTM D 3418 standard testing method. A sample size by 5-7 mg was used. The samples were heated from $60-600^{\circ} \mathrm{C}$ at the heating rate of $10^{\circ} \mathrm{C} / \mathrm{min}$ in a nitrogen-rich atmosphere.

\section{RESULTS AND DISCUSSION Curing Characteristics}

The curing characteristics of the NR/NBR blends determined using a rheometer give some data which can be used to evaluated some parameters such as the cure time $\left(t_{c 90}\right)$, the scorch time $\left(\mathrm{t}_{\mathrm{S} 2}\right)$, and maximum $\left(\mathrm{M}_{\mathrm{H}}\right)$ and minimum torque $\left(\mathrm{M}_{\mathrm{L}}\right)$ as shown in Figure 1 and 2. The vulcanization reaction of the rubber compound can be revealed using curing characteristics data from the rheometer (Fathurrohman et al., 2015). Figure 2 shows that the minimum torque $\left(\mathrm{M}_{\mathrm{L}}\right)$ that reflects the minimum viscosity of the composites tends to increase with an increase in the MBS loading, but it will decrease when the MBS loading is greater than 5 phr. MBS gave higher $M_{L}$ at any loading than blends without MBS. The maximum torque $\left(\mathrm{M}_{\mathrm{H}}\right)$ tends to decrease with an increase in the

MBS loading in the blends. Better processability is due to a decrease in the viscosity assigned to decreased $M_{H}$ related to crosslink density. These phenomena indicates that the presence of MBS improved the processability of the blends. The optimum curing time $\left(\mathrm{t}_{\mathrm{c} 90}\right)$ and scorch time $\left(\mathrm{t}_{\mathrm{S} 2}\right)$ were

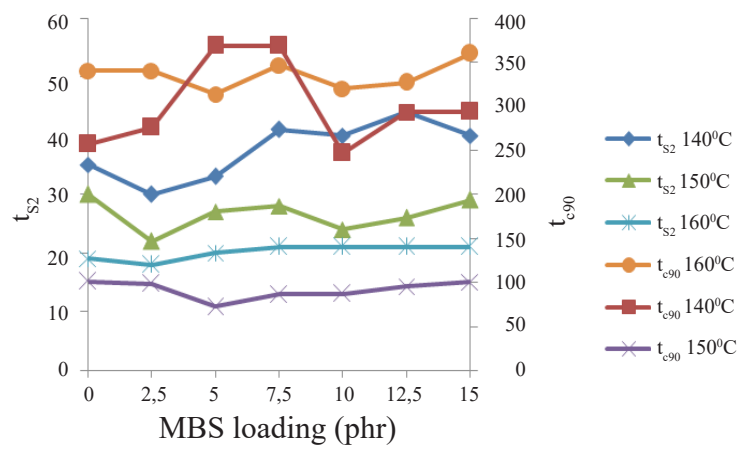

Figure 1. $t_{\mathrm{s} 2}$ and $t_{c 90}$ of the NR/NBR/MBS blends.

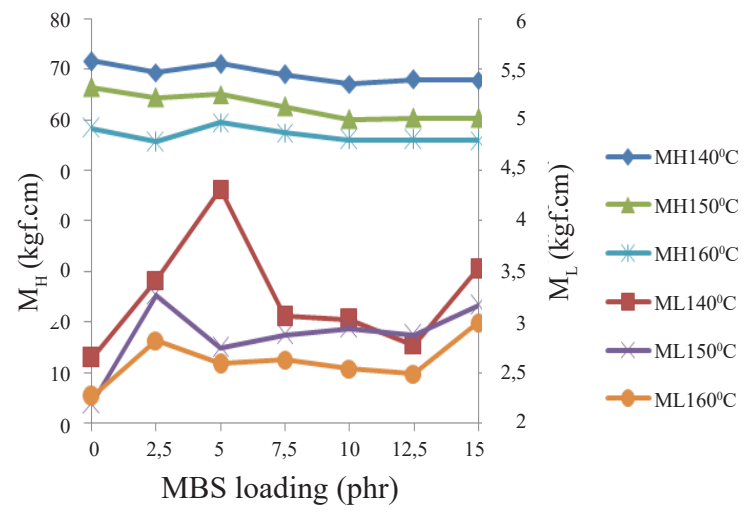

Figure 2. $M_{H}$ and $M_{L}$ of the $N R / N B R / M B S$ blends. 
not influenced by MBS loading. The increasing of vulcanization temperature will reduce the scorch and the optimum curing time because heat accelerates a reaction. The maximum and minimum torque also decreases with an increased in the temperature. Torque is an amount of force needed to process the blends (Mayasari \& Yuniari, 2016), thus, the magnitude of torque needed at a higher temperature is not equal to the one required at a lower temperature. The heat also produces energy that can accelerate a reaction.

The delta torque is associated with crosslink density (Jovanović et al., 2009). The crosslink density is one of the important properties affecting the major characteristics of vulcanized rubber (ElSabbagh \& Yehia, 2007). Figure 3 shows that the delta torque of the blends at 140,150 , and $160^{\circ} \mathrm{C}$ is shown at the MBS loading. The addition of MBS as a compatibilizer increasing the delta torque, but it decreases at the MBS loading which is higher than $5 \mathrm{phr}$. This happens because, at a certain point of MBS, polymers cannot accomodate MBS and filler movement. Filler overload makes the poor dispersion and in turn, causes the crosslink density becomes lower. Lower crosslink density is associated with lower delta torque.

The delta torque of the NR/NBR blends increases with a decrease in the vulcanization temperature. The addition of MBS as a compatibilizer increases the delta torque, but it decreases at loading of MBS higher than $5 \mathrm{phr}$.

\section{Vulcanization Kinetics}

The process of vulcanization kinetics can be obtained from the torque-time data from the rheograph. Chemical reactions can be generally modeled in differential equations such as the equation (3):

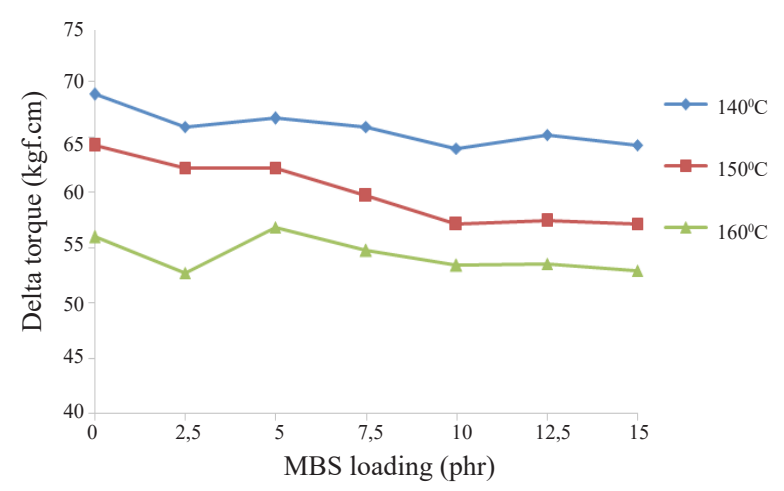

Figure 3. The delta torque of the NR/NBR/MBS blends at 140,150 and $160{ }^{\circ} \mathrm{C}$. $\frac{\mathrm{d} \alpha}{\mathrm{dt}}=\mathrm{k}(\mathrm{T}) \cdot \mathrm{f}(\alpha)$

where the conversion ratio, $\alpha$, at a given time $\mathrm{t}$ is defined using the equation:

$\alpha=\frac{M_{t}-M_{L}}{M_{H}-M_{L}}$

Assuming that the vulcanization process follows first-order kinetics. The kinetics equation is expressed in equation (5):

$\ln \frac{\mathrm{M}_{\mathrm{H}}-\mathrm{M}_{\mathrm{L}}}{\mathrm{M}_{\mathrm{H}}-\mathrm{M}_{\mathrm{t}}}=\mathrm{kt}$

where $M_{t}$ is the torque at time $t, M_{L}$ and $M_{H}$ are the minimum and maximum torque. $\mathrm{M}_{t}$ values of $25 \%$ and $45 \%$ torque change were chosen to estimate the rate constant in this work (Nampitch \& Buakaew, 2006). The vulcanization rate $\mathrm{k}$ was obtained from the slope.

To obtain the activation energy, Equation (5) was combined with the Arrhenius in Equation (6) because the vulcanization rate depends on the reciprocal temperature

$\mathrm{k}=\mathrm{A} \exp \left(-\frac{\mathrm{E} \alpha}{\mathrm{RT}}\right)$

or

$\ln \mathrm{k}=\ln \mathrm{A}-\frac{\mathrm{E} \alpha}{\mathrm{R}} \frac{1}{\mathrm{~T}}$

where $\mathrm{A}$ is the pre-exponential factor, $\mathrm{R}$ is the gas constant, $\mathrm{T}$ is the absolute temperature, and $\mathrm{E} \alpha$ is the apparent activation energy for the curing process. The activation energy was calculated based on the slope shown in Figure 4, while the CRI, the rate constant, and activation energy are summarized in Table 2.

Table 2 shows that the addition of MBS as a compatibilizer did not significantly affect the CRI and the rate constant. The CRI and the rate constant increased as the temperature increased. The highest activation energy was reached by Compound P2. The energy activation increased with an increase in MBS loading, but at the optimum level, it would decrease. It may happen because the crosslink density of the composites with MBS loading greater than $5 \mathrm{phr}$ decreases so that the energy required to break the bond is lower than that of the composite with higher MBS loading. All of the composites shows that all of the correlation coefficients are approaching one. It 


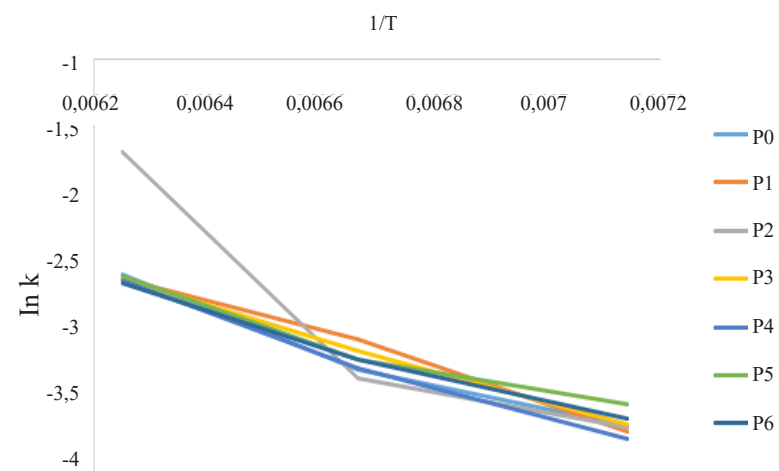

Figure 4. The Arrhenius plot for NR/NBR/MBS blends obtained from the rheographs.

shows that first-order kinetics can be used in this calculation.

\section{Mechanical properties}

The effect of MBS loading $(0-15 \mathrm{phr})$ on the mechanical properties of the blends was investigated. The tensile strength (TS), elongation at break (EB), and shore hardness are summarized in Figure 5. The NR/NBR blend without any compatibilizer has lower tensile strength than the blend with $2.5 \mathrm{phr}$ MBS. But with higher MBS loading, the tensile strength tends to decrease. The presence of MBS in NR/NBR blends improves the tensile strength due to better distribution of NBR in the NR matrix. It improves interfacial adhesion of NR/NBR blends by reducing the interfacial energy between phases. MBS can help improve filler dispersion to the rubber matrices so that it can be a good compatibilizer. But at the optimum level, it causes tensile strength decreases. The blends without MBS have the highest elongation (339\%). MBS loading gives the highest elongation at 5 phr, then the elongation tends to decrease with an increase in MBS (Figure 5b). A decrease in the

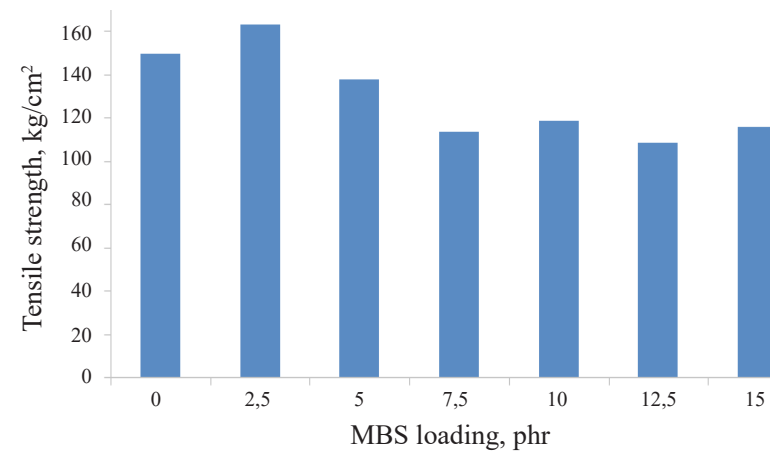

(a)

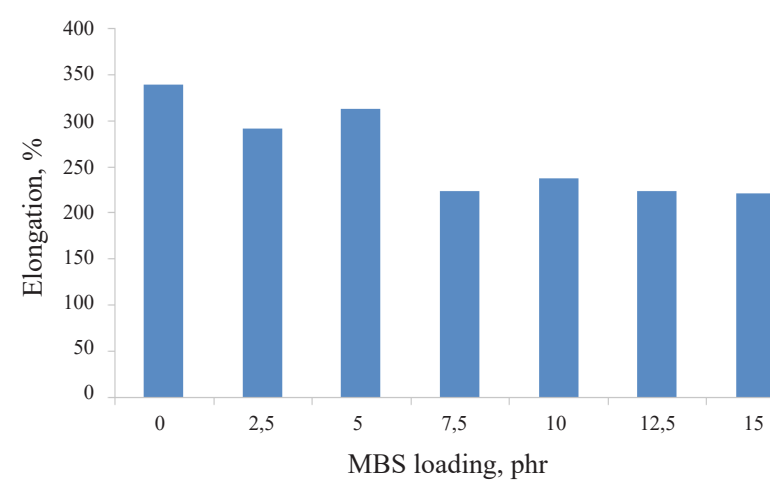

(b)

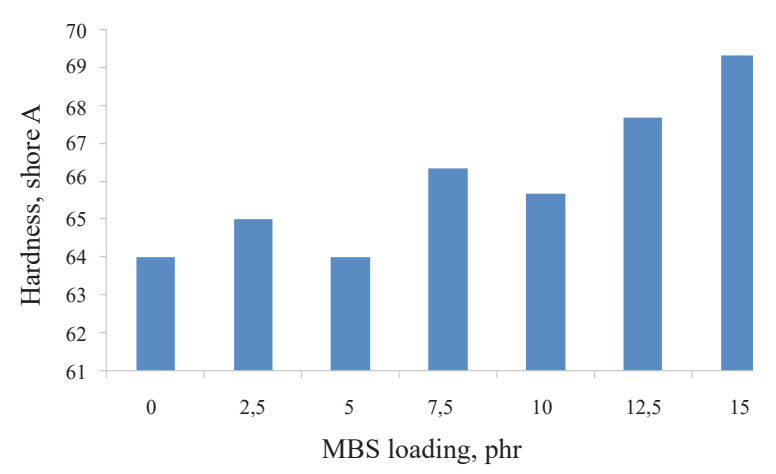

(c)

Figure 5. Mechanical properties of NR/NBR/ MBS blends: (a) tensile strength, (b) elongation, (c) hardness.

Table 2. The cure rate index (CRI), the rate constant,and activation energy of the compound.

\begin{tabular}{cccccccc}
\hline \multirow{2}{*}{ Compound } & \multicolumn{5}{c}{$\mathrm{CRI}\left(\mathrm{sec}^{-1}\right)$} & \multicolumn{3}{c}{$\mathrm{k}\left(1000 \mathrm{x} \mathrm{sec}^{-1}\right)$} & \multirow{2}{*}{$\mathrm{E} \alpha(\mathrm{kJ} / \mathrm{mol})$} \\
\cline { 2 - 6 } & $140^{\circ} \mathrm{C}$ & $150^{\circ} \mathrm{C}$ & $160^{\circ} \mathrm{C}$ & $140^{\circ} \mathrm{C}$ & $150^{\circ} \mathrm{C}$ & $160^{\circ} \mathrm{C}$ & \\
\hline P0 & 0.45 & 1.41 & 3.13 & 25.3 & 38.4 & 76.8 & 10.30 \\
P1 & 0.41 & 1.32 & 3.03 & 24.4 & 47.7 & 74.1 & 10.41 \\
P2 & 0.30 & 2.22 & 3.70 & 25.2 & 35.8 & 187.5 & 18.45 \\
P3 & 0.30 & 1.72 & 3.23 & 25.6 & 43.8 & 74.2 & 9.93 \\
P4 & 0.48 & 1.59 & 3.70 & 23.2 & 38.8 & 73.5 & 10.76 \\
P5 & 0.40 & 1.45 & 3.57 & 29.7 & 41.2 & 75.6 & 9.13 \\
P6 & 0.39 & 1.41 & 3.03 & 26.9 & 41.4 & 71.8 & 9.60 \\
\hline
\end{tabular}


elongation implies that MBS improves the compatibility of the blends. It may happen because of the compatibilizer dispersion to the rubber phase leading to the stiffening of the rubber chain resulting in the blends having good resistance to stretch (Markovi et al., 2017). Figure 5(c) shows that the blend without MBS has the lowest hardness. The hardness tends to increase as MBS loading increases, except $5 \mathrm{phr}$ loading. The flexibility and elasticity of the rubber chain decreases in the presence of MBS, which also increases the rigidity and hardness of the blends. It may happen because an increase in MBS makes the rubber matrix become full so that the rubber vulcanizate becomes tight and stiff.

\section{Swelling Properties}

The interaction between polymeric materials and oil poses a problem in some elastomers. NBR has excellent oil-resistance properties, NR is a non-polar rubber that is easily dissolved in oil or non-polar solvents. Swelling measurement using oil IRM 903 was performed to investigate oil resistance of the NR/NBR blends. The swelling percentages of the blends after immersion in oil IRM 903 at room temperature for 24 hours are presented in Figure 6. The blend without a compatibilizer has a greater swelling percentage $(22,57 \%)$ than a vulcanizate with MBS with up to $7.5 \mathrm{phr}$ MBS loading. But in MBS loading more than $7.5 \mathrm{phr}$, it produces a higher swelling percentage.

\section{Morphological Observation}

Morphological investigation delivers important information about filler dispersion and compatibility of the rubber blend. A scanning electron microscope (SEM) was used to investigate the surface morphology of the blends shown in Figure 7. Rubber blends are miscible when their components form a single homogeneous phase, and immiscible when they show several distinct phases. The NR/NBR vulcanizates without MBS showed typical rubber phase separation (Figure 7b) due to poor interfacial adhesion between the NR and NBR phase resulting from dissimilar polarity (Angnanon et al., 2011). Two distinct phases, NR (black) and NBR (gray), indicate the immiscibility of the components in the blends (Bansod et al., 2016). The rubber blends with MBS show that there is no phase separation identified on the tensile fracture surface of the NR/NBR blends (Figures 7(c)-(h)). It can be concluded that MBS

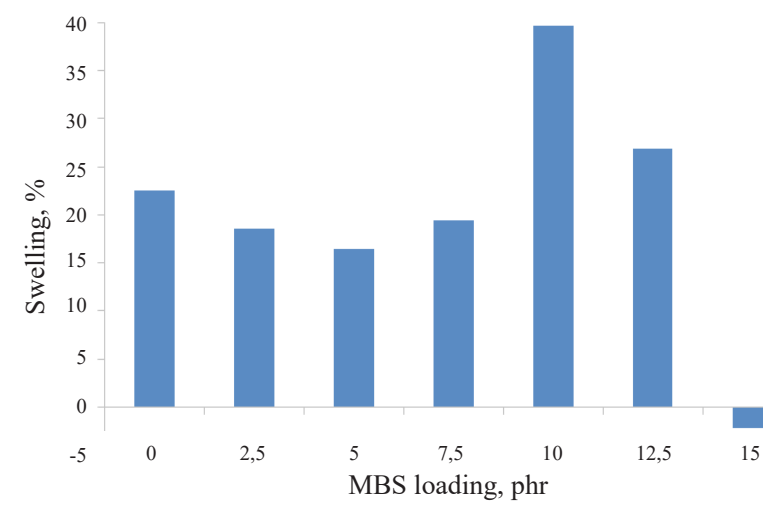

Figure 6. Swelling percentages of NR/NBR/MBS blends.

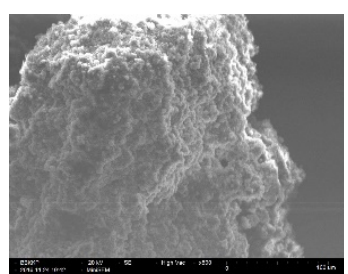

(a)

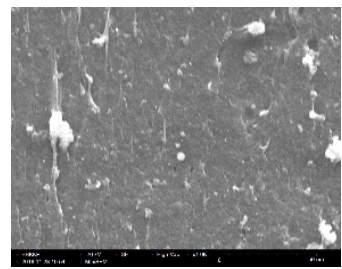

(c)

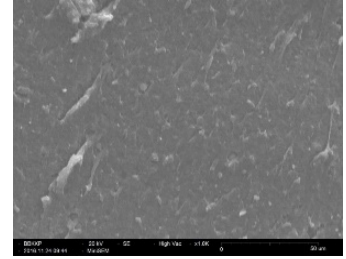

(e)

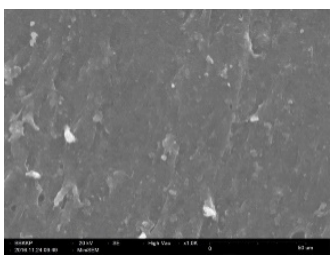

$(\mathrm{g})$

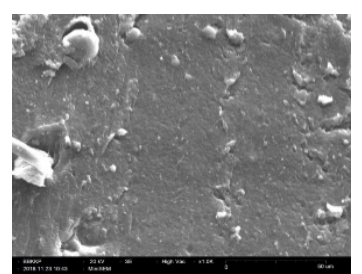

(b)

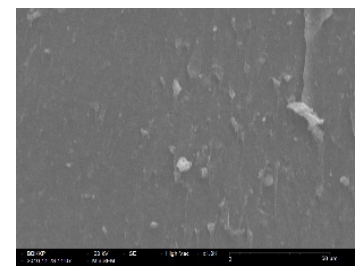

(d)

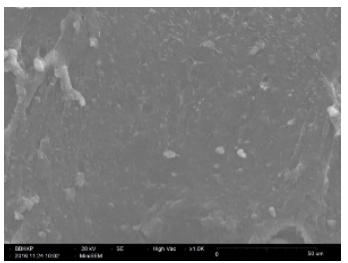

(f)

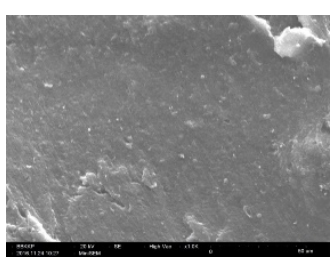

(h)
Figure 7. SEM micrographs of the tensile fracture surface of 50/50 (w/w) of NR/NBR blends (a) MBS 500x (b) wihout MBS 1000x (c) $2.5 \mathrm{phr}$ MBS 1000x (d) $5 \mathrm{phr}$ MBS 1000x (e) $7.5 \mathrm{phr}$ MBS 1000x (f) $10 \mathrm{phr}$ MBS 1000x (g) $12.5 \mathrm{phr}$ MBS 1000x and (h) 15 phr MBS 1000x. 
is the effective compatibilizer for NR/NBR blends to improve the interfacial adhesion to get better mechanical properties.

\section{Thermal Analysis}

The compatibility of the polymer blends can be studied using differential scanning calorimetry (DSC), which measure the glass transition temperature $(\mathrm{Tg})$ and the melting temperature $(\mathrm{Tm})$ of polymeric materials.

A DSC thermogram of the NR/NBR blend without MBS shows only one Tm, i.e. at $469.57{ }^{\circ} \mathrm{C}$ in Figure 8. With the addition of 2.5 phr MBS, Tm is displayed at $466.53{ }^{\circ} \mathrm{C}$. Increased MBS on the blend at $10 \mathrm{phr}$ shows 3 peak Tm, namely at $254.62{ }^{\circ} \mathrm{C}, 367.12{ }^{\circ} \mathrm{C}$, and $467.05{ }^{\circ} \mathrm{C}$. Miscible blends will show a single sharp peak while immiscible blends will show some sloping peak (P4). It may happen because NR is non-polar while NBR is polar. At crystallization temperature, polymers will lose random network arrangement and form intermolecular bonds so that the polymer molecules can be joint more easily to form a bond during the process of crystallization under exothermic conditions.

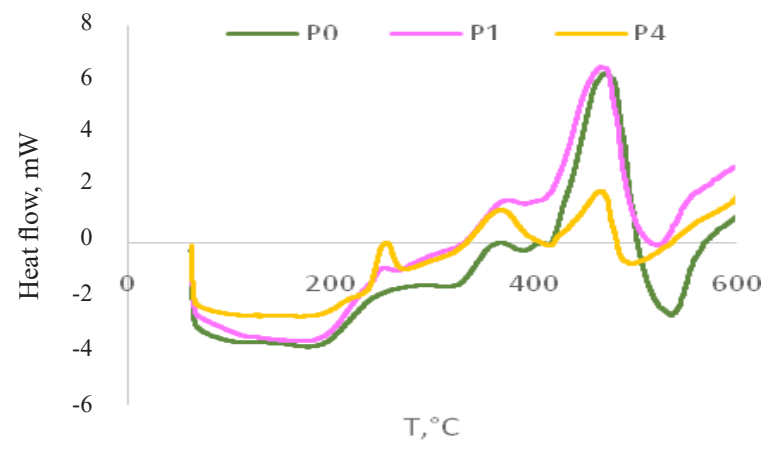

(a)

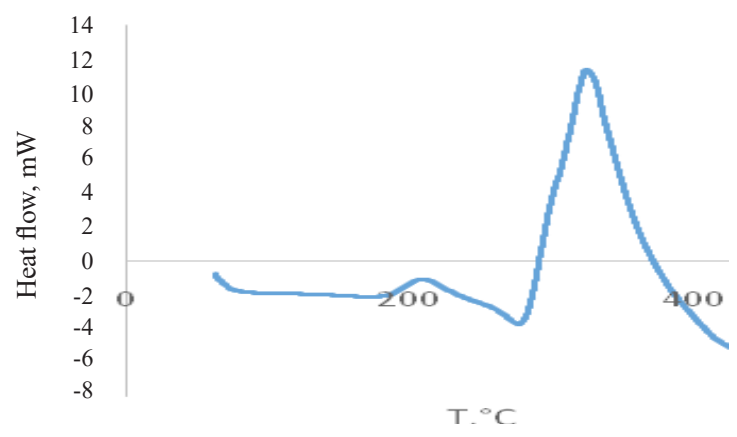

(b)

Figure 8. DSC curve of (a) MBS and (b) NR/NBR blends.

\section{CONCLUSIONS}

Based on the experiment, it can be concluded that MBS can be applied as a compatibilizer for highly polar dissimilarity of NR/NBR. The addition of MBS increases the delta torque and minimum torque $\left(\mathrm{M}_{\mathrm{L}}\right)$, but it decreases at MBS loading which is higher than $5 \mathrm{phr}$. The maximum torque $\left(\mathrm{M}_{\mathrm{H}}\right)$ tends to decrease with an the increasing MBS loading in the blends. The optimum curing time $\left(\mathrm{t}_{90}\right)$, scorch time $\left(\mathrm{ts}_{2}\right)$, CRI, and rate constant of the blends are not significantly influenced by MBS loading. The highest activation energy was reached by compound $\mathrm{P} 2$. The energy activation increases as MBS loading increases, but at the optimum level, it will decrease. The vulcanization temperature influences the processability of the compound. MBS loading by $2.5 \mathrm{phr}$ produces the best tensile strength $\left(163.67 \mathrm{~kg} / \mathrm{cm}^{2}\right)$, elongation at break $(292.67 \%)$, hardness (65 shore A), and swelling (18.6\%). The presence of MBS improves interfacial adhesion and compatibility.

\section{ACKNOWLEDGMENT}

The authors would like to thank the Center for Leather, Rubber, and Plastics, Ministry of Industry, Indonesia for financial support.

\section{REFERENCES}

Abu-Abdeen, M., \& Elamer, I. (2010). Mechanical and swelling properties of thermoplastic elastomer blends. Materials and Design, 31(2), 808-815, https://doi.org/10.1016/j.matdes.2009.07.059

Ahmad, H., Ismail, H., \& Rashid, A. (2015). ENR50 compatibilized natural rubber/recycled acrylonitrile-butadiene rubber blends. Sains Malaysiana, 44(6), 835-842.

Alipour, A., Naderi, G., Bakhshandeh, G. R., Vali, H., \& Shokoohi, S. (2011). Elastomer nanocomposites based on NR/EPDM/organoclay: morphology and properties. Polymer Processing, 26, 48-55.

Angnanon, S., Prasassarakich, P., \& Hinchiranan, N. (2011). Styrene/acrylonitrile graft natural rubber as compatibilizer in rubber blends. PolymerPlastics Technology and Engineering, 50(April 2011), 1170-1178, https://doi.org/10.1080/03602559.2011.574667

Bansod, N. D., Kapgate, B. P., Das, C., \& Das, A. (2016). Compatibilization of natural rubber/nitrile rubber blends by sol-gel nano-silica generated by in situ method. Journal of Sol-Gel Science and Technology, 80(2), 548-559. https://doi.org/10.1007/s10971-016-4114-0

Clikeman, R. R. (1981). European Patent Application (number 81302919.6). 
El-Sabbagh, S., \& Yehia, A. (2007). Detection of crosslink density by different methods for natural rubber blended with SBR and NBR. Egyptian Journal of Solids, 30(2), 157.

Fathurrohman, M. I., Maspanger, D. R., \& Sutrisno, S. (2015). Vulcanization kinetics and mechanical properties of ethylene propylene diene monomer thermal insulation. Bulletin of Chemical Reaction Engineering \& Catalysis, 10(2), 104-110. https://doi.org/10.9767/bcrec.10.2.6682.104-110

Ismail, H., Galpaya, D., \& Ahmad, Z. (2009). Comparison of properties of polypropylene (PP)/ virgin acrylonitrile butadiene rubber (NBRv) and polypropylene (PP)/ recycled acrylonitrile butadiene rubber ( NBRr ) blends. Polymer-Plastics Technology and Engineering, 48, 440-445. https://doi.org/10.1080/03602550902725449

Jovanović, V., Budinski-Simendić, J., SamardžijaJovanović, S., Marković, G., \& MarinovićCincović, M. (2009). The influence of carbon black on curing kinetics and thermal aging of acrylonitrile-butadiene rubber. Chemical Industry and Chemical Engineering Quarterly, 15(4), 283-289. https://doi.org/10.2298/CICEQ0904283J

Kantala, C., Wimolmala, E., Sirisinha, C., \& Sombatsompop, N. (2009). Reinforcement of compatibilized NR/NBR blends by fly ash particles and precipitated silica. Polymer Advance Technology, 20, 448-458. https://doi.org/10.1002/pat.1293

Kinasih, N. A., \& Fathurrohman, M. I. (2016). Ketahanan n-pentana dan sifat mekanis vulkanisat karet perapat dari campuran karet alam/akrilonitril-butadiena dengan kompatibiliser. Majalah Kulit, Karet, dan Plastik, 32(2), 99-110. https://doi.org/10.20543/mkkp.v32i2.1013

Markovi, G., Pirot, T., Marinovi, M., Sciences, N., Science, N., \& Sad, N. (2017). Rheological and mechanical properties of wood flour filled polyisoprene/chlorosulphonated polyethylene rubber blends. Chemical Industry and Chemical Engineering Quarterly, 13(4), 186-191. https://doi.org/10.2298/CICEQ0704186M

Marković, G., Marinović-Cincović, M., Radovanović, B., \& Budinski-Simendić, J. (2007). Rheological and mechanical properties of wood flour filled polyisoprene/chlorosulphonated polyethylene rubber blends. Chemical Industry and Chemical Engineering Quarterly, 13(4), 186-191.

Mayasari, H. E., \& Yuniari, A. (2016). Effect of vulcanization system and carbon black on mechanical and swelling properties of EPDM blends. Majalah Kulit, Karet, dan Plastik, 32(1), 59-64. https://doi.org/10.20543/mkkp.v32i1.706
Mousavi, S. R., \& Amraei, I. A. (2015). Influence of nanosilica and methyl methacrylate-butadiene-styrene core-shell rubber particles on the physicalmechanical properties and cure kinetics of diglycidyl ether of bisphenol-A-based epoxy resin. High Performance Polymers, 1-11. https://doi.org/10.1177/0954008315600228

Nampitch, T., \& Buakaew, P. (2006). The effect of curing parameters on the mechanical properties of styrene-NR elastomers containing natural rubber-graft-polystyrene. Kasetsart Journal (Natural Science), 40, 7-16.

Rajasekar, R., Pal, K., Heinrich, G., Das, A., \& Das, C. K. (2009). Development of nitrile butadiene rubber-nanoclay composites with epoxidized natural rubber as compatibilizer. Materials and Design, 30(9), 3839-3845. https://doi.org/10.1016/j.matdes.2009.03.014

Ren, L., Zhang, M. Y., Wang, Y. R., Na, H., \& Zhang, H. $X$. (2014). The influence of the arrangement of styrene in methyl methacrylate / butadiene / styrene on the properties of PMMA / SAN / MBS blends, Polymer Advance Technology, 25, 273-278. https://doi.org/10.1002/pat.3232

Siriyong, T., \& Keawwattana, W. (2012). Utilization of different curing systems and natural zeolite as filler and absorbent for natural rubber/nitrile rubber blend. Kasetsart Journal (Natural Science), 930, 918-930.

Takahashi, J., Watanabe, H., Nakamoto, J., Arakawa, K., \& Todo, M. (2015). In situ polymerization and properties of methyl methacrylate-butadienestyrene resin with bimodal rubber particle size. Polymer Journal, 38(8), 835-843. https://doi.org/10.1295/polymj.PJ2005203

Thomas, S. P., Mathew, E. J., \& Marykutty, C. V. (2012). Nanomodified fillers in chloroprene-rubber-compatibilized natural rubber / acrylonitrile -butadiene rubber blends. Jounal of Applied Polymer Science, 124(5), $4259-4267$.

Wisittanawat, U., Thanawan, S., \& Amornsakchai, T. (2014). Mechanical properties of highly aligned short pineapple leaf fiber reinforced-nitrile rubber composite: Effect of fiber content and bonding agent. Polymer Testing, 35, 20-27. http://doi.org/10.1016/j.polymertesting.2014.02.003 